\title{
The Effect of Explicit vs. Implicit Instruction on the Learnability of English Consonant Clusters by Iranian Learners of English
}

\author{
Ruhollah Khanbeiki \\ English Department, Science and Research Branch, Islamic Azad University, Gorgan, Iran \\ Seyed Jalal Abdolmanafi-Rokni (Corresponding author) \\ English Department, Golestan University, Gorgan, Iran \\ E-mail: j.abdolmanafi@gmail.com
}

Doi:10.7575/aiac.alls.v.6n.2p.103

Received: 28/11/2014

URL: http://dx.doi.org/10.7575/aiac.alls.v.6n.2p. 103

Accepted: 01/02/2015

\begin{abstract}
The present study was aimed at providing the English teachers across Iran with a good and fruitful method of teaching pronunciation. To this end, sixty female intermediate EFL learners were put in three different but equivalent groups of 20 based on the results of a pronunciation pre-test. One of the groups received explicit instruction including exposure to the correct pronunciation of consonant clusters, extra examples, and explanations. The kind of treatment for the second group was implicit including only exposure to the correct pronunciation of such clusters. The third group, serving as the control group, received no instruction on pronunciation. After ten sessions of instruction, all the participants were provided with the post-test in which they were to read aloud 50 words containing initial and final consonant clusters while they were recorded. The results of ANOVA showed that although they were all the same in the pre-test, they had performed differently on the post-test, demonstrating that different treatments had various impacts on learning pronunciation. The results of Tukey test showed that although the participants in the implicit group had progressed during the course, the explicit instruction was the best method in improving participants' pronunciation. To compare the groups' mean scores two by two, t-test was also used. The results of this test showed that explicit instruction is better than the implicit instruction which in turn is better than the control group.
\end{abstract}

Keywords: pronunciation, consonant cluster, explicit teaching, implicit teaching

\section{Introduction}

Pronunciation is an important aspect of language learning which could form either the main objective of a class or a section of it. Thus, teachers may allocate the whole class time to teaching pronunciation, or they may choose to indirectly draw the students' attention to pronunciation while the main goal of the lesson is the other aspects of language such as listening or reading. The issue of pronunciation or phonology can be dealt with at two levels, segmental and supra-segmental. While the former, i.e. segmental level, deals with the role of individual sounds and sound segments in a language, the latter, i.e. supra-segmental level, pays a special attention to the features such as stress, rhythm, and intonation.

Correct pronunciation of English sounds is crucially important in terms of communication since in the majority of cases the replacement of one sound for another will result in changes in meaning and hence will affect the flow of communication. Therefore, a main goal of the teachers must be training the students to pronounce sounds the same way as native speakers of the target language. The fact that few second language learners have acquired high levels of proficiency has caused many researchers as well as teachers to assume that this goal, i.e. acquiring native-like pronunciation, is a difficult one for learners (especially adult learners) to get to.

However, one of the objectives most second language learners set for themselves once they start learning a second language is improving their proficiency in pronunciation. In effect, they consider pronunciation as important as, and sometimes more significant than, other aspects of language such as grammar. That's why many of them, when asked, argue that they like to achieve native-like proficiency in L2 pronunciation and it is for the same reason that they usually like their phonological errors to be corrected by the teacher.

Lightbown and Spada (2006) point out that although it is true that foreign accents do not stop communication, many second language learners, especially those who have achieved a high level of knowledge and performance in other aspects of the target language, may like to achieve a particular target language accent in their pronunciation. They continue that "what is clear is that de-contextualized pronunciation instruction is not enough and that a combination of instruction, exposure, and motivation is required" (p. 104). What's more, getting access to native-like pronunciation ability is very difficult for many second language learners to experience. 
On the other hand, a distinction made by different approaches to language teaching regarding the issue of pronunciation is whether this aspect of language could be taught implicitly or explicitly. The belief in those approaches that emphasize the implicit teaching of pronunciation is that the issue is among those aspects of language that cannot be taught explicitly but has to be "picked up through exposure" (Richards \& Renendya, 2002, p. 175). Others, however, believe in explicit teaching asserting that teaching can be very important in helping learners improve their pronunciation (Richards \& Renendya, 2002, p. 176). In spite of all the research done in the area of explicit versus implicit teaching of pronunciation, it still is not clear which one is better than the other. Moreover, there are many teachers who are still doubtful about the status of pronunciation and whether and how it should receive systematic attention in a language course.

\section{Literature Review}

Pronunciation plays a very crucial role in communication; therefore, in today's truly called world of communication, one needs to have an acceptable command of this skill to be able to successfully communicate in English and also to evade misunderstandings due to poor pronunciation. In Iran and many other countries, where English serves as a foreign language, little or no attention is devoted to teaching this skill in most English classes. Actually, the authentic production of the sounds of the language (i.e. native-like pronunciation) is considered trivial and unimportant by the educational system in Iran since the general belief here is that the only way people can have contact with English is through reading; therefore, they think it is not necessary that students waste their time learning skills other than reading.

Accordingly, neither are teachers prepared to devote any class time to teaching pronunciation, nor students have tendency to pay considerable attention to this important skill. That is why most Persian learners of English in Iran have serious problems in accurately pronouncing English words and are unable to communicate efficiently in English. Moreover, their poverty and weakness in pronunciation has affected the other skills necessary to learn a language and as a result no improvement can often be seen in students' general knowledge about English.

One of the reasons for the lack of inclination on the teachers' side to include pronunciation instruction in their classes may be that there is no pertinent scientific and empirical research in this area, one that can present a good and applicable approach to achieving the goal. In fact, there are many good and acceptable research studies done in this area outside the country but the findings are usually inapplicable to the educational system in Iran. Therefore, doing the research that examines the phonological problems of the learners inside the country is of considerably high importance.

From both a practical and a theoretical point of view, it is important to understand the difference between implicit and explicit learning mechanisms and the role they play in second language learning. One of the most frequently asked questions in language teaching is whether pronunciation should be taught explicitly, and one of the central issues in the psycholinguistics of second language acquisition is whether adults can learn the L2 pronunciation fully through the same implicit learning mechanisms used by the child learning a first language. Before discussing which one of the two approaches, explicit or implicit, is more effective for teaching L2 pronunciation to adult learners, it seems necessary to present a rather detailed definition of the terms implicit/explicit and consonant clusters.

\subsection{Explicit and Implicit Learning and Teaching}

Implicit versus explicit linguistic knowledge are two distinct processes for learning a second language. These two constructs have drawn the attention of many researchers over the past decade or so. Brown (2000, p. 285) claims that "in the explicit category are the facts that a person knows about language and the ability to articulate those facts in some way". To him, "implicit knowledge", however, "is information that is automatically and spontaneously used in language tasks".

An example of implicit knowledge can be the way children acquire phonological, syntactic, and pragmatic rules of their first language without being able to explicitly explain those rules. In fact, as a child learns his first language implicitly, he gradually becomes able to perform the language in spontaneous discourse, but has no access to the rules governing his performance. The central issue in implicit learning, as many researchers working in this field believe, is lack of consciousness or awareness of the structure being learned. DeKeyser (2003, p. 314), for example, defines implicit learning as "learning without awareness of what is being learned".

Many researchers have also proposed some models using the explicit/implicit distinction. Bialystok (1982), for example, has used the terms analyzed and unanalyzed knowledge as synonymous with the concepts of explicit and implicit. He defines unanalyzed knowledge as "the general form in which we know most things without being aware of the structure of that knowledge". On the other hand, he continues "learners are overtly aware of the structure of analyzed knowledge" (p. 285-6). Thus, at the analyzed end, as Bialystok asserts, learners have the ability to express complex rules governing the language while at the unanalyzed extreme of this knowledge dimension, learners are only able to perform language rules without being aware of those rules.

According to Ellis (1993), implicit knowledge can be identified in two kinds: "formulaic knowledge and rule-based knowledge". Formulaic knowledge, as said by him, contains ready-made chunks of language, i.e. whole utterances, such as 'I don't know' or utterance frames with one or more empty slots, such as 'Can I have a--------?'. However, "Rulebased knowledge", to him, "consists of generalized and abstract structures which have been internalized" (Ellis, 1993, p. 94). Thus, the knowledge in both kinds is "intuitive", not conscious. Ellis continues that native speakers know a large number of formulas which they have learned as unanalyzed units. They also know rules that enable them to understand and produce new sentences without conscious effort. Taken together, implicit knowledge of rules is largely hidden 
because the way these rules are represented in the mind is unknown. Such knowledge can only be manifested in actual performance (both comprehension and production) (Ellis, 1993).

DeKeyser (2003) has distinguished implicit learning from the concept it is often confused with in the second language literature: "inductive learning". According to him, although it is generally believed that inductive and deductive learning must be accompanied by implicit and explicit learning respectively, there exists the possibility to meet combinations of explicit-inductive and implicit-deductive. In fact, according to DeKeyser, inductive learning (going from the particular to the general, from examples to rules) and implicit learning (learning without awareness) are two "orthogonal concepts". He also gives an example of each kind of learning (2003, p. 314):

Via traditional rule teaching, learning is both deductive and explicit. When students are encouraged to find rules for themselves by studying examples in a text, learning is inductive and explicit. When children acquire linguistic competence of their native language without thinking about its structure, their learning is inductive and implicit. The combination of deductive and implicit is less obvious, but the concept of parameter setting in Universal Grammar could be seen as an example; supposedly learners derive a number of characteristics of the language being learned from the setting of the parameter, and this clearly happens without awareness.

Ellis (1993) has made a distinction between the concepts: explicit/implicit and declarative/procedural which may appear to be very similar, but in fact, they are not. He explains that although the terms explicit/implicit are used to represent the conscious or intuitive knowledge L2 learners have, the terms declarative/procedural are used to refer to the amount of control L2 learners have over L2 knowledge i.e. whether they can use the L2 knowledge with effort through controlled processing or effortlessly through automatic processing.

Hence, as mentioned above, the concepts which play an essential role in both implicit and explicit learning of language rules are the absence or presence of consciousness, awareness, attention, noticing, and focus on form. Using such concepts, DeKeyser (2003) has compared explicit and implicit teaching maintaining that an instructional treatment is considered explicit if rule explanation forms part of the instruction (deduction) or if learners are asked to attend to particular forms and try to find the rules by themselves (induction). On the contrary, he continues, when neither rule explanation nor directions to attend to particular forms are part of the treatment, that treatment is considered implicit.

\subsection{Consonant Clusters}

The present study, as mentioned above, is intended to offer an approach to teaching English consonant clusters, which is an aspect present in English syllable structure. In order to provide a good definition of consonant clusters, the reader must first be familiar with the term syllable, in addition to being aware of the basic elements of a syllable so that he can more easily deal with the structure of English syllables. Ladefoged (2006, p. 242) defines syllable as "the smallest possible unit of speech". In fact, a syllable, as Keshavarz (2008, p. 46) explains, "is a unit of pronunciation typically larger than a single sound and smaller than a word". The word 'ne.ver.the.less', for example, contains four syllables. The most common type of syllable in language contains a consonant before the vowel, often represented as CV (Yule, 1996). However, to Yule (1996), a syllable must contain a vowel (or vowel-like) sound. To be precise, the vowel element is necessary to the structure of a syllable.

To have an accurate definition of English consonant clusters, it seems necessary to describe the basic elements of a syllable. A syllable, as said by Yule (1996), can be divided into the 'onset' (one or more consonants) and the 'rime' that consists of a vowel which is called 'nucleus', plus any following consonant(s), referred to as 'coda'. According to Yule, both the onset and the coda can contain more than one consonant, which is known as consonant cluster. Therefore, consonant cluster can be defined as a group of consonants in a syllable with no intervening vowels. The combination of /st/, for example, is a consonant cluster (CC) as 'onset' in the word 'stand' and as 'coda' in the word 'best'.

Keshavarz (2008) also defines consonant clusters as the sequences of consonants, happening together, at the beginning or the end of a syllable. He continues that for such sequences of clusters to be called consonant cluster, they must be in the same syllable. In other words, he states that if such sequences of consonants belong to different syllables, they form 'abutting consonants', not consonant clusters. An example of abutting clusters can be the sounds $/ \mathrm{m} / \mathrm{and} / \mathrm{p} /$ in the word 'jum.per'. Many languages of the world are more restrictive than English as far as consonant clusters are concerned. Many others do not permit consonant clusters at all. Persian, for example, does not allow initial consonant clusters (i.e. as the onset), or more than two consecutive consonants in final position (as the coda) (Keshavarz, 2008).

HaghShenas (2006) maintains that the basic structure of the kind of syllable that can be found in Persian words is $\mathrm{CV}(\mathrm{C}(\mathrm{C}))$, i.e. we can have combinations of $\mathrm{CV}-\mathrm{CVC}$ or CVCC as the only permitted syllables in Persian. English, however, is not so restrictive in terms of consonant clusters. The basic structure of English syllables is $(((C) C) C) \mathrm{V}(\mathrm{C}(\mathrm{C}(\mathrm{C}(\mathrm{C}))))$. The longest possible initial cluster is three sounds, as in 'split'; the longest possible final cluster is four sounds, as in 'twelfths', 'bursts' and 'strengths'.

Actually, there are some rules, called phonotactics, to the combination and the arrangement of such consonants in a given language; that is, such consonants cannot occur in any random order to form a word (Keshavarz, 2008; Yule, 1996). In other words, it is the phonological rules of a given language that decide which phonemes can begin a word, end a word, and follow each other. For the English syllables consisting of three consonants in the initial position, the first one must always be /s/, the second one a voiceless stop $(/ \mathrm{p} /, / \mathrm{t} /, / \mathrm{k} /)$ and the third one an approximant $(/ \mathrm{r} /, / 1 /, / \mathrm{w} /)$ (Yule, 1996; O'Grady, Dobrovolsky, \& Aronoff, 2002). 
However, the phonological rule for those syllables that have two consonants in the initial position is not so restrictive. It is noticeable in English that in casual conversational speech, large consonant clusters, especially those occurring in final position, are frequently reduced as they are usually difficult for native speakers to pronounce (Keshavarz, 2008). Thus,

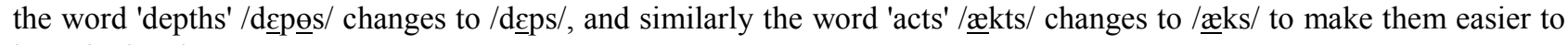
be articulated.

Actually, "elision", which is defined as the omission of a difficult sound to simplify the articulation of a word, is only one example of "co-articulation effects", which is defined by Ladefoged (2006, p. 292) as "the overlapping of the adjacent articulations". Another example of such an effect is "assimilation", which happens when one sound changes into another because of the influence of the neighboring sounds (Yule, 1996). An example of assimilation can be changing the sound $/ \mathrm{n} /$ into $/ \mathrm{m} /$ in the word 'input'. Indeed, if the speakers of a language constantly violate the regular patterns of assimilation and elision used in that language, the result would be "artificial-sounding talk" (Yule, 1996).

The researches done in the area of consonant clusters have shown that those L2 learners whose first language syllable structure does not allow initial or final consonant clusters have great difficulty pronouncing the words containing such clusters correctly, i.e. without vowel insertion. Initial consonant clusters, for example, have proven to cause great difficulty for Persian learners of English as such clusters are not allowed in Persian language (Keshavarz, 2008).

Having explained the meanings of explicit/implicit dichotomy as well as consonant clusters, in order to achieve the purpose of the study, the following seven null hypotheses are formulated as follows:

$\mathrm{H}_{1}$ : The implicit teaching of English consonant clusters is not helpful for Iranian intermediate learners of the language to learn the correct pronunciation of consonant clusters.

$\mathrm{H}_{2}$ : The explicit teaching of English consonant clusters is not helpful for Iranian intermediate learners of the language to learn the correct pronunciation of consonant clusters.

$\mathrm{H}_{3}$ : There is no significant difference between the implicit and explicit way of teaching consonant clusters in Iranian EFL learners.

$\mathrm{H}_{4}$ : There is no significant difference between explicit way of teaching consonant clusters and the control group in Iranian EFL learners.

$\mathrm{H}_{5}$ : There is no significant difference between implicit way of teaching consonant clusters and the control group in Iranian EFL learners.

\section{Methodology}

\subsection{Participants}

The sample in this study included 60 female intermediate EFL learners studying English at a language school in Gorgan. Their age ranged from 15 to 17 and were selected from a whole population of 152 students who were initially asked to participate in the study from three different language schools in Gorgan, Iran. Before these 60 students who formed the final sample of the study were chosen, the goal of the study was generally described to the whole population to see whether or not they could continue with the research. To control for the maturation effect, those who were studying at higher intermediate or advanced levels were asked not to participate in the study. Eventually, the remaining 60 students showed their willingness and ability to help the researcher with the study.

\subsection{Materials}

Two pronunciation tests were used in this study: a pre-test, and a post-test. The main purpose of the pre-test was to help the researcher put the students in three different but equivalent and homogeneous groups of 20 . The pre-test included 50 words, half of which contained different initial consonant clusters and the other half covered different final consonant clusters. The words chosen for the students to pronounce were those they already were familiar with; therefore, the researcher was sure that the words' level of difficulty is in accordance with the participants' knowledge of the English language. The students were asked to read the words aloud while they were voice-recorded.

In the test the researcher listened to how each student read the words, giving a score to that student based on the way he pronounced initial or final consonant clusters. For the scores to be reliable, two other English teachers analyzed the students' pronunciations and scored them, counting their errors in pronouncing different consonant clusters. It's worth mentioning that the three scorers had attended teacher training periods, and thus were highly experienced and skilled in doing so. In this study, they were asked to score the students only based on their pronunciation of consonant clusters, and to pay no attention to other aspects of pronunciation, such as stress. This way the scores given by the three scorers could be reliable. The scales used for rating the results of the tests were interval. The course of instruction included ten sessions for each group, and lasted about a month. Afterwards, the main test of the study was administered and the performances of the students in all the three groups were analyzed. The same test was also chosen for the post-test. The aim of the post-test was to determine the effects of the two kinds of treatment under question, i.e. explicit vs. implicit, on the students. The post-test was given to the samples right after the treatment period. In this test also the students were to read the related list of words aloud while they were voice-recorded.

\subsection{Procedure}

As explained before, before the treatment period a pre-test was given to all of the samples to make sure they are unaware of the rules to be taught (i.e. English consonant clusters) and also that they are all at the same level. Based on the samples' performances on the pre-test, they were classified into three equivalent groups of 20 , two treatment groups 
(explicit and implicit) and a control group. Then the students in each treatment group were exposed to ten sessions of instruction, either implicitly or explicitly. What follows will explain the differences between the three groups in detail.

\subsubsection{The Explicit Group}

At the very beginning of the first session the teacher explicitly provided the students with a detailed explanation of what he meant by English consonant cluster rules. In fact, giving some examples, the teacher taught the rule to the students and compared the syllable structures of the two languages in question (i.e. English and Persian). He also talked about the probable difficulties Persian learners of English may face in pronouncing such clusters in English. Then, to present some more examples of how English words containing consonant clusters are pronounced, he wrote the list of words used for on the board and asked the students to repeat after him. Then, the teacher asked each student to read the words on the board aloud and corrected their errors after all the students finished pronouncing the words.

The following sessions started with the participants listening carefully to the teacher who read the list of words. Having done that, the teacher explained the meanings of the difficult words and tried to attract the students' attention to the correct pronunciation of the new words. One of the participants was then asked to read the words aloud. The other students and the teacher listened to him carefully for the probable errors in pronouncing consonant clusters. The errors were mentioned and discussed in the class. Whenever necessary, the teacher provided the students with an explanation of the syllable structure of the words including consonant clusters, presented some extra examples, and even compared the rule in English with that in Persian. In the remaining sessions, the most widely used technique was asking the participants to present lectures while the teacher was paying attention to how they pronounced consonant clusters, simultaneously correcting their errors. Two lecturers made speeches of about 10 minutes each session. Other students also took notes and jotted down the lecturer's errors. After each presentation, the participants posed questions on the lecture they had listened to, and the lecturer answered them. Problems in pronouncing the words containing consonant clusters were scrutinized by the teacher and discussed after the questions had been answered. The initial part of the following session was devoted to talking about the previous session's lecturers' pronunciation errors. All throughout the instruction, the participants' attention was attracted to the correct and acceptable pronunciation of the words with consonant clusters.

\subsubsection{The Implicit Group}

The most important factor distinguishing the explicit group from the implicit one was that the participants in this group were left unaware of the rule underlying English consonant clusters. That is to say, no time of the class was dedicated to the explanation and discussion of consonant cluster rules. Therefore, the students were ignorant of the content and type of the test they were going to take at the end of the course. However, the other materials that the participants in this group received were rather similar to that of the explicit group. They had the opportunity to listen to the teacher reading the words. They could also read the words aloud. Just like the explicit group, the first three sessions were devoted to reading the list of words and working on the meanings of difficult words to make sure the students had no problems understanding the meaning of the words. Afterwards, the students read the words chosen for the test aloud and their pronunciation errors were corrected by the teacher.

Instead of discussing consonant cluster rules, the teacher tried to ask students to make sentences using the words with consonant clusters. The words were covered this way in three sessions and during the rest of the instruction course, the students were asked to present lectures and the teacher corrected their errors related to the pronunciation of consonant clusters. Each session, two students were asked to give short lectures of about 10 minutes. The teacher and the other students listened to them and wrote down their grammatical and pronunciation errors. The lectures were recorded and given to the lecturers to be checked for the probable mistakes in the next session. Having listened to the lectures, the teacher and the students asked the lecturers questions on the content of their speeches. Their errors were mentioned and discussed at the very beginning of the next session. Even though the students' errors in the pronunciation of consonant clusters were corrected by the teacher and by the other students in the class, the students were never informed of the goal of the instruction and the content and type of the test they were going to take at the end of the course.

\subsubsection{The Control Group}

The participants in the control group received no instruction regarding consonant clusters at all, neither explicitly nor implicitly. In fact, they only attended the classes, but their errors concerning pronunciation of such clusters were not corrected at all. Actually, their presence in the study could only help the researcher prove that instruction, being either explicit or implicit, can make a difference. In other words, the existence of a control group would confirm that any kind of change in the behavior of the treatment groups was due the method of instruction rather than chance or other extraneous variables such as the maturation effect.

\subsection{Data Analysis}

For hypotheses one and two, the participants' performances on the three tests were scored and the means, standard deviations, standard errors, etc. were determined for the different groups. Since the study required that the researcher compare the performances of the three groups (explicit, implicit and control) and since the scale of the dependent variable was interval while those in the independent variable were nominal, the assumptions for using ANOVA were met. Thus, the data were analyzed using a series of ANOVAs. The ANOVAs used provided an F ratio that showed the ratio of the amount of variation between the groups to the amount of variation within the groups. Because ANOVA only provides information on whether or not the three groups differ but provides no information as to the location or the source of the difference, some Tukey tests were also used to determine which treatment (explicit or implicit) led to 
better results. In fact, the Tukey tests were used when the $\mathrm{F}$ ratio was significant. The significance level for the ANOVAs was set at $0.01(\mathrm{p}<.01)$, and that of the Tukey tests was set at $.05(\mathrm{p}<.05)$.

For the hypotheses three, four and five, an independent t-test was used to compare the mean scores of each two groups (i.e. explicit vs. implicit; explicit vs. control; and implicit vs. control). In fact, assumptions for using t-test were met in these hypotheses. In other words, the scores in each group were normally distributed (NORMAL DISTRIBUTION OF SCORES) and the variances for the scores of the two groups were equal (HOMOGENIETY OF VARIANCES). The pvalue set for the t-test was $0.05(\mathrm{p}<.05)$.

\section{Results}

\subsection{Descriptive Statistics}

After the participants took the two tests, their scores were carefully analyzed and the descriptive statistics such as means, standard deviations, standard errors, etc. were measured, as shown in Table 1.

Table 1. Descriptive statistics of the performances of the groups on different tests of the study

\begin{tabular}{|c|c|c|c|c|c|c|c|c|c|}
\hline \multicolumn{10}{|c|}{ Descriptive statistics } \\
\hline & & \multirow[t]{2}{*}{$\mathrm{N}$} & \multirow[t]{2}{*}{ Mean } & \multirow[t]{2}{*}{$\begin{array}{l}\text { Std. } \\
\text { Deviation }\end{array}$} & \multirow[t]{2}{*}{ Std. Error } & \multicolumn{2}{|c|}{$\begin{array}{l}\text { 95\% Confidence Interval for } \\
\text { Mean }\end{array}$} & \multirow[t]{2}{*}{ Min. } & \multirow[t]{2}{*}{ Max } \\
\hline & & & & & & Lower Bound & Upper Bound & & \\
\hline \multirow[t]{4}{*}{ Pre-test } & Control & 20 & 52.00 & 5.024 & .917 & 50.12 & 53.88 & 44 & 60 \\
\hline & Implicit & 20 & 52.00 & 3.562 & .650 & 50.67 & 53.33 & 46 & 59 \\
\hline & Explicit & 20 & 52.00 & 4.631 & .846 & 50.27 & 53.73 & 45 & 60 \\
\hline & Total & 60 & 52.00 & 4.399 & .464 & 51.08 & 52.92 & 44 & 60 \\
\hline \multirow{4}{*}{$\begin{array}{l}\text { Post- } \\
\text { test }\end{array}$} & Control & 20 & 53.00 & 4.835 & .883 & 51.19 & 54.81 & 44 & 60 \\
\hline & Implicit & 20 & 58.00 & 5.502 & 1.005 & 55.95 & 60.05 & 48 & 68 \\
\hline & Explicit & 20 & 70.00 & 6.198 & 1.132 & 67.69 & 72.31 & 60 & 80 \\
\hline & Total & 60 & 60.33 & 9.026 & .951 & 58.44 & 62.22 & 44 & 80 \\
\hline
\end{tabular}

\subsection{ANOVA Analysis in Pre-test}

The results of the ANOVA analysis in the pretest, as illustrated in Table 2., showed that the F observed is not statistically significant when the $\mathrm{p}$-value is above $0.01[\mathrm{~F}(2,87)=0.00, \mathrm{p}>.01]$. That is, there were no significant differences between the three groups (explicit, implicit, and control) in the pre-test. In other words, the findings of the $\mathrm{F}$ ratio in the pre-test demonstrated that the three groups were quite homogeneous and equivalent at the beginning of the study. Thus, it can be concluded that the process of classifying the participants into the equivalent groups has been done quite successfully. It is worth mentioning that because the observed $\mathrm{F}$ was not statistically significant, no post-hoc analysis (such as Tukey test) was used for the pre-test.

Table 2. ANOVA Analysis in the Pre-test

\begin{tabular}{llllll}
\hline & Sum of squares & $\mathrm{df}$ & Mean square & $\mathrm{F}$ & Sig. \\
\hline Between groups & .000 & 2 & .000 & .000 & 1.000 \\
Within groups & 1722.000 & 57 & 19.793 & & \\
Total & 1722.000 & 59 & & & \\
\hline
\end{tabular}

\subsection{ANOVA Analysis in Post-test}

The results of the ANOVA analysis in the post-test, as shown in Table 3, confirmed that the F observed is statistically significant at the $\mathrm{p}$-value of $0.01[\mathrm{~F}(2,87)=74.618, \mathrm{p}<.01]$. To be exact, there were significant differences between the means of the three groups (explicit, implicit, and control) in the post-test. In other words, the findings of the $\mathrm{F}$ ratio in the post-test demonstrated that the three groups had changed a great deal after the 10 sessions of instruction and were no longer the same as they were so before the treatment. In fact, the results of the ANOVA analysis proved that there was a strong significant relationship between the type of instruction and the students' accuracy in correctly pronouncing the words containing consonant clusters. 
Table 3. ANOVA analysis in the post-test

\begin{tabular}{llllll}
\hline & Sum of squares & df & Mean square & F & Sig. \\
\hline Between groups & 4580.000 & 2 & 2290.000 & 74.618 & .000 \\
Within groups & 2670.000 & 57 & 30.690 & & \\
Total & 7250.000 & 59 & & & \\
\hline
\end{tabular}

\section{4 Use of Tukey tests in the post-test}

The ANOVA done in the post-test indicated that the different treatments of the study led to significantly different results in learning the rules of English consonant clusters, but it provided no information as which treatment was more conducive to a more accurate pronunciation of the words containing such clusters. To do so, a Tukey test was performed, as suggested by Mackey and Gass (2005) and Brown (1988), to compare the pairs of the groups' means individually (i.e. to compare the means of the groups two by two). According to Brown (1988, p. 177), "use of the ordinary t-test is not appropriate for making multiple comparisons". The descriptive statistics and also the Tukey test for the post-test are illustrated in Tables 4 and 5, respectively.

Table 4. descriptive statistics of the Tukey test for the immediate post-test

\begin{tabular}{llllllc}
\hline (I) Group & (J) Group & $\begin{array}{l}\text { Mean differences } \\
\text { (I-J) }\end{array}$ & Std. Error & Sig. & \multicolumn{2}{c}{$95 \%$ confidence interval } \\
\cline { 6 - 7 } & & & & & Lower bound & Upper bound \\
\hline control & Implicit & $-5.00^{*}$ & 1.430 & .002 & -8.41 & -1.59 \\
& Explicit & $-17.00^{*}$ & 1.430 & .000 & -20.41 & -13.59 \\
\multirow{3}{*}{ Emplicit } & Control & $5.00^{*}$ & 1.430 & .002 & 1.59 & 8.41 \\
& Explicit & $-12.00^{*}$ & 1.430 & .000 & -15.41 & -8.59 \\
& Control & $17.00^{*}$ & 1.430 & .000 & 13.59 & 20.41 \\
& Implicit & $12.00^{*}$ & 1.430 & .000 & 8.59 & 15.41 \\
\hline
\end{tabular}

${ }^{*}$. The mean difference is significant at the .05 level.

Table 5. Tukey test for the post-test TukeyHSD ${ }^{\mathrm{a}}$

\begin{tabular}{|c|c|c|c|c|}
\hline \multirow[t]{2}{*}{ GROUP } & \multirow[t]{2}{*}{$\mathrm{N}$} & \multicolumn{3}{|c|}{ Subset for alpha $=.05$} \\
\hline & & 1 & 2 & 3 \\
\hline Control & 20 & 53.00 & & \\
\hline Implicit & 20 & & 58.00 & \\
\hline Explicit & 20 & & & 70.00 \\
\hline Sig. & & 1.000 & 1.000 & 1.000 \\
\hline
\end{tabular}

Means for groups in homogeneous subsets are displayed.

a. Uses Harmonic Mean Sample size $=20.000$

Regarding the descriptive statistics (mean, lower bound, upper bound, etc.), illustrated in Table 5, the results of the Tukey (HSD) test used in the post-test showed that the means of the three groups are significantly different from each other. Thus, they fall into three different groups $(1,2$, and 3). Actually, the statistics obtained from the Tukey test showed the mean of the control group ( $\mathrm{x}$ control: 53.00) is significantly different from those of the implicit ( $\mathrm{x}$ implicit: 58.00) and explicit ( $\mathrm{x}_{\text {explicit }}$ : 70.00) groups, respectively. In fact, the Tukey test showed that except for the control group, which had not changed significantly, the participants in the two treatment groups (i.e. implicit and explicit) had improved after the treatment period, although to different degrees. As a result, it can be maintained that both the explicit and the implicit treatments are effective in teaching consonant clusters to Iranian intermediate learners of English. Therefore, according to the findings obtained from the Tukey test, both the first and the second hypotheses are rejected at the p-value of .05. In other words, both the implicit and the explicit teaching of the English consonant clusters are beneficial to the correct pronunciation of consonant clusters and there is a $5 \%$ probability that the research findings are due to factors other than the research variables, such as chance.

The other thing the Tukey test showed was that there was a significant difference between the mean of implicit group ( $\mathrm{x}$ implicit: 58.00 ) and that of the explicit group ( $\mathrm{x}_{\text {explicit }}$ : 70.00). That's why they are put in two different groups in the Tukey test (i.e. group 2 for the implicit group and group 3 for the explicit group). In fact, the statistics obtained from this test showed that although both treatments (i.e. implicit and explicit) are helpful for the teaching of consonant clusters to Iranian intermediate learners, their effectiveness is not the same. In other words, the participants in the explicit group had performed much better than those in the implicit one, indicating that this kind of treatment is more helpful than the 
implicit one for the teaching of consonant cluster rules to Iranian intermediate learners. Table 6 below shows the group statistics for the implicit and explicit groups.

Table 6. Group statistics for the implicit and explicit groups

\begin{tabular}{|c|c|c|c|c|c|c|}
\hline & Groups 123 & & $\mathrm{~N}$ & Mean & $\begin{array}{l}\text { Std. } \\
\text { Deviation }\end{array}$ & $\begin{array}{ll}\text { Std. } & \text { Error } \\
\text { Mean } & \end{array}$ \\
\hline \multirow[t]{2}{*}{ ContImpliExpli } & dimension 1 & implicit & 20 & 58.0000 & 6.49696 & 1.45277 \\
\hline & & explicit & 20 & 70.0000 & 5.75372 & 1.28657 \\
\hline
\end{tabular}

As it is shown in table 6 above, the mean of the implicit and explicit groups are 58.00 and 70.00 respectively. Table 7 below also shows the actual result of the independent t-test.

Table 7. Result of the independent t-test for the implicit and explicit groups

Levene's Test for
Equality of Variances t-test for Equality of Means

\begin{tabular}{|c|c|c|c|c|c|c|c|c|}
\hline & & $\mathrm{F}$ & Sig. & $\mathrm{T}$ & $\mathrm{df}$ & $\begin{array}{l}\text { Sig. } \\
\text { tailed) }\end{array}$ & $\begin{array}{l}\text { (2-Mean } \\
\text { Difference }\end{array}$ & $\begin{array}{l}\text { Std. B } \\
\text { Difference }\end{array}$ \\
\hline \multirow[t]{2}{*}{ ContImpliExpli } & $\begin{array}{l}\text { Equal } \\
\text { variances } \\
\text { assumed }\end{array}$ & .709 & .405 & 5.926 & 38 & .000 & -11.50000 & 1.94056 \\
\hline & $\begin{array}{l}\text { Equal } \\
\text { variances } \\
\text { not assum }\end{array}$ & & & 5.926 & 37.453 & .000 & -11.50000 & 1.94056 \\
\hline
\end{tabular}

The Levene's test of equality of variances had the Sig of .709 which was higher than .05 , meaning that the assumption of equality of variances has been met. Therefore, we look at the first row to analyze the difference. The independent $t-$ test was run to compare the mean scores of the implicit and explicit groups. As it can be seen in table 5 above, $t(38)=$ 5.92, $p=0.000<0.05$. Accordingly, the null hypothesis "There is no significant difference between the implicit and explicit way of teaching consonant clusters in Iranian EFL learners" was rejected. The explicit group performed better on the post-test. Table 8 below shows the group statistics for the control and explicit groups.

Table 8. Group statistics for the control and explicit groups

\begin{tabular}{lllllll}
\hline & Groups 1 23 & & $\mathrm{N}$ & Mean & Std. Deviation & Std. Error Mean \\
\hline \multirow{2}{*}{ ContImpliExpli } & \multirow{2}{*}{ dimension1 } & control & 20 & 53.0000 & 5.51553 & 1.23331 \\
\cline { 3 - 7 } & & explicit & 20 & 70.0000 & 5.75372 & 1.28657 \\
\hline
\end{tabular}

As it is shown in table 8 above, the mean of the control and explicit groups are 53.00 and 70.00 respectively. Table 9 below shows the actual result of the independent t-test.

Table 9. Result of the independent t-test for the control and explicit groups

$$
\begin{aligned}
& \text { Levene's Test for } \\
& \text { Equality of Variances t-test for Equality of Means }
\end{aligned}
$$

\begin{tabular}{|c|c|c|c|c|c|c|c|c|}
\hline & & $\mathrm{F}$ & Sig. & $\mathrm{T}$ & $\mathrm{df}$ & $\begin{array}{l}\text { Sig. } \\
\text { tailed) }\end{array}$ & $\begin{array}{l}\text { (2-Mean } \\
\text { Difference }\end{array}$ & $\begin{array}{l}\text { Std. Error } \\
\text { Difference }\end{array}$ \\
\hline \multirow[t]{2}{*}{ ContImpliExpli } & $\begin{array}{l}\text { Equal } \\
\text { variances } \\
\text { assumed } \\
\end{array}$ & .000 & 1.000 & -9.258 & 38 & .000 & -16.50000 & 1.78222 \\
\hline & $\begin{array}{l}\text { Equal } \\
\text { variances not } \\
\text { assumed }\end{array}$ & & & 9.258 & 37.932 & .000 & -16.50000 & 1.78222 \\
\hline
\end{tabular}

The Leven's test of equality of variances had the Sig of 1.000 which was higher than .05 , meaning that the assumption of equality of variances has been met. Therefore, we look at the first row to analyze the difference. The independent $t-$ 
test was run to compare the mean scores of the control and explicit groups. As it can be seen in table 9 above, $t(38)=$ $9.25, p=0.000<0.05$.

Accordingly, the null hypothesis "There is no significant difference between explicit way of teaching consonant clusters and the control group in Iranian EFL learners" was rejected. The explicit group performed better on the post-test. Table 10 below shows the group statistics for the implicit and control groups.

Table 10. Group statistics for the control and implicit groups

\begin{tabular}{llllll}
\hline & Groups 1 23 & $\mathrm{N}$ & Mean & Std. Deviation & Std. Error Mean \\
\hline ContImpliExpli & \multirow{2}{*}{ dimension 1 control } & 20 & 53.0000 & 5.51553 & 1.23331 \\
\hline implicit & 20 & 58.0000 & 6.49696 & 1.45277 \\
\hline
\end{tabular}

As it is shown in table 10 above, the mean of the control and implicit groups are 53.00 and 58.00 respectively. Table 11 below shows the actual result of the independent $t$-test.

Table 11. Result of the independent t-test for the implicit and control groups

\begin{tabular}{|c|c|c|c|c|c|c|c|c|}
\hline & & \multicolumn{7}{|c|}{$\begin{array}{l}\text { Levene's Test for } \\
\text { Equality of Variances t-test for Equality of Means }\end{array}$} \\
\hline & & $\mathrm{F}$ & Sig. & $\mathrm{T}$ & $\mathrm{df}$ & $\begin{array}{l}\text { Sig. } \\
\text { tailed) }\end{array}$ & $\begin{array}{l}\text { (2-Mean } \\
\text { Difference }\end{array}$ & $\begin{array}{l}\text { Std. Error } \\
\text { Difference }\end{array}$ \\
\hline \multirow[t]{2}{*}{ ContImpliExpli } & $\begin{array}{l}\text { Equal } \\
\text { variances } \\
\text { assumed }\end{array}$ & .833 & .367 & 2.624 & 38 & .012 & -5.00000 & 1.90567 \\
\hline & $\begin{array}{l}\text { Equal } \\
\text { variances } \\
\text { not assume }\end{array}$ & & & 2.624 & 37.025 & .013 & -5.00000 & 1.90567 \\
\hline
\end{tabular}

The Levene's test of equality of variances had the Sig of .367 which was higher than .05 , meaning that the assumption of equality of variances has been met. Therefore, we look at the first row to analyze the difference. The independent ttest was run to compare the mean scores of the control and implicit groups. As it can be seen in table 11 above, $t(38)=$ $2.62, p=0.012<0.05$. Accordingly, the null hypothesis "There is no significant difference between implicit way of teaching consonant clusters and the control group in Iranian EFL learners" was rejected. The implicit group performed better on the posttest.

\section{Discussion and Conclusion}

The aim of the present study was to make a comparison between two different but common methods of teaching pronunciation (implicit versus explicit) to Iranian learners of English (i.e. to examine which one of the two is more effective for the teaching of consonant clusters to Persian learners of English), and to determine the more efficient approach to teaching this aspect of pronunciation in the educational system of the country.

The reason why the participants in the control group did not improve at all in the pronunciation of consonant clusters could be that such clusters are not salient in English phonology, and as such cannot be learnt without instruction. This is to say although such clusters occur very frequently in English phonology, they are semantically redundant; thus violating them has little effect on the flow of communication. In other words, they may not be acquired by the students unless their attention is drawn to the presence of such clusters through instruction. Consequently, it is the role of instruction to help them notice the gap between what they say and the true form to say that specific feature.

On the other hand, the participants in the explicit group outperformed the other two groups on the post-test. This is because the rules underlying consonant clusters were explicitly presented to them. In fact, explicitly presenting the participants with the rules underlying consonant clusters helped them learn such clusters sooner than the participants in the other two groups; thus, the finding is in line with the finding of the study conducted by Abdolmanafi-Rokni (2009). In broader terms, it means that explicit instruction helps the students notice the difference between what they say and what they mean, and accordingly, causes them to improve better and faster in the target language. The conclusion is that explicit instruction can increase the speed of learning and thus can produce more positive effects on pronunciation in a classroom setting in a short run in comparison to implicit instruction.

Although many English teachers in the state educational system still believe that teaching pronunciation to Iranian students is ineffective, and that correct pronunciation of English is too complicated to be learned under current conditions, the present study quite obviously showed that Persian learners were certainly capable of mastering 
pronunciation. The only thing necessary to achieve this goal is to work definitely and explicitly based on the scientific findings of the relevant research.

Whereas one can find great numbers of studies which have investigated the same issue, very few studies have actually been done within the educational system in Iran to determine whether the findings of these studies are applicable in the existing situation or not. The present study, however, tried to deal with this issue of applicability and proved that while implicit instruction may to some extent lead to the learning of English consonant clusters, Persian learners of English can surely benefit much more through explicit instruction, which includes further examples, rule explanation, comparing the differences between the syllable structures of the two languages, and of course, attracting the students' attention to what they are being taught.

\subsection{Pedagogical Implications}

As the results of the study proved that explicit teaching of English consonant clusters, including presenting phonetic symbols, pronunciation rules, and stress patterns and providing extra examples, could obviously lead to better results than the implicit one, it can have the following implications for the students, teachers, educational policy-makers, and textbook designers.

1. In order to learn the English pronunciation, students had better use monolingual dictionaries which provide them with the exact pronunciation of the English language through phonetic symbols.

2. Educational policy-makers should organize courses for teachers to refresh their knowledge of the features of the phonetic system of the target language. This way, teachers can first of all gain a better command of the English pronunciation and then be much more successful in teaching pronunciation to their students.

3. Teachers can teach pronunciation through offering the students pronunciation rules and stress patterns. They can also provide the students with phonetic symbols of the target language sounds. In other words, they can direct their instruction toward the explicit teaching as much as possible.

4. Textbook designers should pay much more attention to the pronunciation part included in the students' textbooks and had better let the learners have more chance and time to work on this salient aspect of the English language. For instance, they can provide more exercises in this part and some pronunciation rules can also be included in this part to help the students learn the correct pronunciation more easily.

\section{References}

Abdolmanafi-Rokni, S.J. (2009). A Comparative Study of the Effect of Explicit-inductive and Explicit-deductive Grammar Instruction in EFL Contexts. Language in India, 9(11), 151-175.

Bialystok, E. (1982). On the relationship between knowing and using linguistic forms. Applied linguistics, 3, 181-206.

Brown, H.D. (2000). Principles of language learning and teaching. Fourth edition. White Plains: Longman.

Brown, J.D. (1988). Understanding research in second language learning. Cambridge: Cambridge University Press.

DeKeyser, R. (2003). Implicit and explicit learning. In Doughty \& Long (eds.), The handbook of second language acquisition. Oxford: Blackwell Publishing.

Ellis, N. (1993). Rules and instances in foreign language learning: interactions of explicit and implicit knowledge. European Journal of Cognitive Psychology, 5, 289-318.

HaghShenas A .M. (2006). Ava Shenasi (Phonetics). Tenth edition. Tehran: Agah.

Keshavarz, M. H. (2008). Contrastive analysis and error analysis. Tehran: Rahnama Press.

Ladefoged, (2006). A course in phonetics ( $5^{\text {th }}$ ed.). Los Angeles: Thomson Wadsworth.

Lightbown, M. \& Spada, N. (2006). How languages are learned. Oxford: Oxford University Press.

O'Grady, W. Dobrovolsky, M. \& Aronoff, M. (2002). Contemporary linguistics: An introduction. Tehran: SAMT.

Richards, J.C. \& Renendya, W.A. (2002). Methodology in Language Teaching. Cambridge: Cambridge University Press.

Yule, G. (1996). The Study of Language, second Edition. Cambridge, United Kingdom: Cambridge University Press. 